\title{
Notas sobre a tortura em um debate do Primeiro Comando da Capital (PCC) em São Paulo
}

\author{
Camila Nunes Dias* ${ }^{*}$ \\ Mayara de Souza Gomes*
}

\section{Resumo}

Ao longo da sua história, o grupo criminal autodenominado Primeiro Comando da Capital (PCC) constituiu alguns mecanismos regulatórios voltados à administração de conflitos, o exercício de controle social e a aplicação de punições, tanto nas prisões quanto nas periferias em que alcançou hegemonia. Os dispositivos conhecidos como debates expressam a configuração assumida pelos expedientes voltados à resolução de conflitos e têm se destacado pela variedade de demandas que lhes são reportadas. Os casos considerados mais complexos têm sido identificados como aqueles que envolvem assuntos de "vida e morte". Neste texto, partindo da análise de um processo crime que apurou práticas de tortura na cidade de São Paulo e que se referia à ocorrência de um debate do tipo "vida e morte", discutimos como estes debates têm recorrido ao uso da tortura para operacionalizar as decisões tomadas pelos membros do PCC com a finalidade de obter confissão e, ao mesmo tempo, punir indivíduos acusados de violar a "disciplina do crime". Além disso, ressaltamos como valores sociais e morais, amplamente disseminados, fundamentam a ética regulatória das práticas do mundo do crime e são mobilizados para orientar as ações deliberadas por estes agentes, legitimando, inclusive, o uso da violência como forma de resolução de conflitos e de punição.

Palavras-chave: tortura, PCC, organização criminal, violência, debate.

$\bar{*}$ Universidade Federal do ABC, Santo André, SP, Brasil. 


\section{Notes on torture in a debate by the Capital's First Command (PCC) in São Paulo}

\section{Abstract}

Throughout its history, the criminal group called the Capital's First Command (Primeiro Comando da Capital - PCC) has constituted regulatory mechanisms aimed at conflict management, the exercise of social control, and the application of punishments, both in prisons and in the urban outskirts where it has reached hegemony. The devices known as debates express the configuration assumed by the mechanisms aimed at resolving conflicts and are of note due to the variety of demands that are reported on them. The cases involving "life and death" issues have been considered to be the more complex ones. In this text, starting from the analysis of a criminal process investigating torture practices in the city of São Paulo and related to the occurrence of a "life and death" debate, we discuss how these debates have resorted to the use of torture to operationalize the decisions taken by the members of the PCC for the purpose of obtaining a confession and, at the same time, punishing individuals accused of violating the "discipline of crime". In addition, we emphasize how widely disseminated social and moral values underpin the regulatory ethics of criminal practices and are mobilized to guide the actions deliberated by these agents and, also, legitimize the use of violence as a way of resolving conflicts and punishment.

Keywords: torture, PCC, criminal groups, violence, debate.

\section{Introdução}

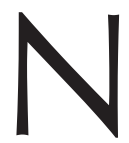

as últimas décadas, diversos grupos de criminosos organizados surgiram nas prisões, estenderam sua influência para além dessas instituições e tornaram-se importantes atores sociais em todos os Estados da federação brasileira. Estes grupos se constituíram enquanto agentes centrais, tanto na transformação de dinâmicas e atividades consideradas ilícitas/ilegais, tais como aquelas associadas à mercância de drogas (Manso; Dias, 2017), quanto na (re)produção de novas sociabilidades, seja em seus espaços originários, como as prisões (Shimizu, 2011; Hirata, 2010; Dias, 2009; Biondi, 2009; Marques, 2009), ou em territórios periféricos 
de diferentes cidades brasileiras (Ruotti, 2016; Biondi, 2014; Dias, 2013; Feltran, 2011; 2010; Hirata, 2010; Telles; Hirata, 2010).

O Primeiro Comando da Capital (PCC), considerado um dos principais grupos criminais brasileiros, surgiu a partir da organização de presos dentro de unidades prisionais paulistas em 1993. Uma multiplicidade de trabalhos realizados ao longo dos últimos anos (Dias, 2013; 2010; 2009; Feltran, 2010; 2011; Biondi, 2009; Marques, 2009) descrevem o surgimento do PCC a partir de um contexto institucional marcado pelo recrudescimento da violência estatal e das históricas violações de direitos dirigidas às pessoas em situação de prisão, que se expressou de forma emblemática no episódio do massacre do Carandiru (ocorrido em outubro de 1992), constituindo-se como um divisor de águas nas dinâmicas prisionais do Estado de São Paulo (Machado et al., 2018; Adorno; Salla, 2007).

Durante a segunda metade da década de 1990, o PCC ampliou sua presença nas unidades carcerárias do Estado (Dias, 2013) e, na década seguinte, transpôs os muros prisionais, capilarizando-se por bairros e regiões periféricas paulistas (Godói, 2015; Feltran, 2011; 2010; Hirata, 2010). Se na primeira década este processo baseou-se no uso da violência, especialmente para enfrentar as resistências que emergiam dentro das prisões, à medida que o PCC passou a consolidar sua influência nestes estabelecimentos, adquirindo, por fim, a hegemonia no sistema carcerário de São Paulo, houve uma significativa redução da violência física, inclusive porque o grupo também se firmou como uma instância de mediação e regulação de conflitos (Dias, 2013; 2009).

Em linhas gerais, grupos criminais como o PCC recorrem à violência física e/ou psicológica como forma de expandir, controlar e derrotar opositores e resolver conflitos nos mercados ilegais, e também como mecanismo de autoridade e poder, além de exercer o controle social nos diferentes lugares e dinâmicas sociais onde passaram a incidir (Ruotti, 2016; Dias, 2013). Neste aspecto, deve-se frisar que a atuação e/ou omissão do Estado em tais contextos e lugares foram igualmente relevantes para se compreender a centralidade que tais grupos adquiriram como agentes produtores de 
novas práticas e sociabilidades (Feltran, 2012; 2011; Telles; Hirata, 2010; Hirata, 2010; Dias, 2009; Biondi, 2009; Marques, 2009).

Ao tomar por escopo de análise a atuação do PCC, pode-se identificar que, ao longo das duas últimas décadas, o grupo constituiu uma série de mecanismos voltados a normalizar condutas e valores, bem como estabelecer formas de controle social e resolução de conflitos, principalmente, mas não só, no mundo do crime (Feltran, 2010; Dias, 2009).

Desde o início da sua atuação, o PCC buscou elaborar registros escritos relacionados aos objetivos e aos princípios ideológicos que deveriam nortear suas práticas (estatutos, cartilhas, dicionário disciplinar), bem como distribuir ordens, decisões, comunicados e orientações gerais ou específicas (salves) que podem ser internos ou externos ao grupo, além de uma série de documentos de registros e controles de cunho econômico (contabilidade de seus diversos setores) e "político", ou seja, em termos da regulações das relações sociais. Neste caso, trata-se de relatórios que, em geral, registram e descrevem os conflitos ocorridos num determinado local, os mecanismos de mediação e de resolução que foram mobilizados para resolver ou encaminhar a solução daqueles problemas e, se for o caso, punir os "responsáveis" por violar as condutas consideradas "certas" (Dias; Salla, 2019).

A atuação do PCC como instância de mediação e regulação de conflitos se sustenta no "proceder", que pode ser considerado como um complexo de práticas, normas de conduta e regras de comportamento que envolvem a formulação e incorporação de concepções éticas quanto às formas de ser e de agir consideradas "certas" no mundo do crime e suas adjacências - isto é, nos círculos próximos a ele, como seus familiares e comunidade local. Na verdade, o "proceder" deriva de moralidades e valores largamente disseminados entre determinados segmentos da população, e já tinha vigência muito antes da emergência do PCC (Hirata, 2010; Marques, 2009; Ramalho, 2002). Contudo, pode-se dizer que o PCC produziu uma homogeneização nestas normas, disseminando-as de maneira mais uniforme, inclusive através da sua cristalização em documentos escritos, de certa forma, constituindo aquilo que passou a ser chamado de "disciplina do Comando". 
Os debates ${ }^{1}$ são os mecanismos centrais através dos quais o PCC operacionaliza a mediação e regulação de conflitos nas prisões e nas "quebradas" (Ruotti, 2016; Feltran, 2011; 2010; Telles; Hirata, 2010; Hirata, 2010). Correspondem a momentos de deliberação coletiva nos quais se discutem problemas e comportamentos, se produzem julgamentos, se definem culpados e inocentes e se delibera sobre a aplicação de punições em relação àqueles que teriam agido em desacordo com a "disciplina" do Comando (Dias, 2010). Feltran (2010) apresenta três níveis quanto à definição dos debates:

(i) há debates que deliberam sobre "pequenas causas", ou desvios de muito pouca gravidade, que podem são resolvidas por uma "ideia" trocada de modo rápido, por indivíduos da localidade em que o desvio ocorreu; (ii) há casos de gravidade moderada, que têm de ser arbitrados pela consulta a outros "irmãos", mais "considerados" no "crime", e as consultas por telefone celular se encarregam disso; e (iii) há, finalmente, casos de vida ou morte, que só se definem após "debates" bastante mais complexos que os primeiros, em que diversos indivíduos que ocupam posições relacionais conhecidas como "torres", produzam uma sentença consensual (Feltran, 2010, p 63).

Feltran (2010) afirma que há gradações entre os debates e que estas variam de acordo com a gravidade dos fatos reportados e das punições previstas como respostas a eles. A legitimidade da punição imposta pelo grupo repousaria exatamente no mecanismo decisório coletivo ao invés de individual, ou seja, que tem como referência o "Comando" e não qualquer um de seus integrantes em específico. Tais decisões devem se basear nos princípios definidos nos documentos normativos do grupo, ainda que estes sejam atualizados e ressignificados a cada situação (Dias, 2009).

Considerando-se as variações de debates descritas por Feltran (2010), procuramos refletir neste artigo como os debates do tipo "vida e morte"

${ }^{1} \mathrm{O}$ termo debate será utilizado neste texto sempre no sentido acima referido, ou seja, como termo nativo, designando o mecanismo utilizado no âmbito do mundo do crime, especialmente do PCC, de mediação e resolução de conflitos. Como a palavra será utilizada neste texto apenas nesse sentido, optamos por não utilizar aspas ou itálico para destacar a referência ao significado nativo do termo. 
podem ser enquadrados como expedientes de tortura. Para tal, partimos da análise de um processo crime ${ }^{2}$ que apurou a participação de supostos membros do PCC em um debate ocorrido em uma comunidade na cidade de São Paulo. Através da análise deste caso, sugerimos que é possível considerar os debates a partir de uma perspectiva diferente em relação àquelas pelas quais esses fenômenos têm sido analisados. Nesse sentido, a proposta é compreender os debates do PCC como expedientes conformadores de contextos propícios a práticas de tortura, inclusive, como expressão institucionalizada, no mundo do crime, do uso intencional da violência física ou psicológica para obter confissão ou impor castigo.

A possibilidade de adotar uma perspectiva analítica matizada por aspectos práticos e teóricos advindos do campo dos estudos sobre a tortura decorre do material utilizado, principalmente pela pluralidade de vozes que estão registradas e relatadas no processo crime que apurou o evento e que será descrito a seguir. Assim, procuramos trazer à tona outras formas de interpretar os debates e, ao mesmo tempo, compreender como este caso pode ilustrar a mobilidade e adaptabilidade da tortura nas dinâmicas relacionais no Brasil.

\section{Narrativas documentais: elementos metodológicos e possibilidades de análise}

Os debates do PCC já foram objeto análise em outras pesquisas (Silvestre, 2018; Ruotti, 2016; Feltran, 2012; 2011; 2010; Hirata, 2010; Marques, 2009; Biondi, 2014; 2009). Algumas utilizaram como fontes de informações em suas abordagens o relato de terceiros (familiares e amigos) que não estiveram presentes em tais eventos, mas que tomaram contato com o debate (Ruotti, 2016; Feltran 2010), com interlocutores que

${ }^{2} \mathrm{O}$ material de análise aqui utilizado provém da pesquisa de nível mestrado de Gomes (2017). No referido trabalho foi constituído um corpus documental composto por 36 inquéritos policiais e processos criminais (um dos quais é o processo aqui utilizado) e que versavam sobre a apuração de crimes de tortura de acordo com a lei 9.455/97, na cidade de São Paulo, entre os anos de 2004 e 2014. Neste trabalho anterior, a análise central se constituia em torno do julgamento do crime de tortura no âmbito do sistema de justiça criminal. 
eventualmente participaram de ações desse tipo (Biondi, 2014; Hirata, 2010; Marques, 2009), enquanto outros abordaram tal discussão a partir da análise de documentos institucionais e narrativas dos atores do sistema de justiça (Silvestre, 2018).

O processo criminal que subsidia a análise aqui proposta possui elementos similares àqueles presentes na abordagem de Silvestre (2018), especialmente porque, em ambos os casos, a narrativa corporificada nos documentos provém de práticas e rotinas dedicadas a investigar e punibilizar indivíduos e que, portanto, expressam um conjunto de descrições e ações oficiais produzidas no sistema de justiça (Oliveira; Silva, 2005). Todavia, o material de análise utilizado aqui apresenta algumas zonas privilegiadas de investigação (Ginsburg, 1989) que se destacam, sobretudo, pela presença da narrativa da vítima em primeira pessoa, que relata a violência por ela suportada e a descrição do fato a partir de sua perspectiva, além de um caderno contendo a íntegra da "ata" (relatório) elaborada pelos indivíduos que aparecem como réus neste processo e que sintetiza as motivações para a instauração do debate. Componentes que permitem explorar um leque mais amplo de práticas, motivos e valores, bem como as nuances contidas no desenrolar desses eventos e nas formas de atuação dos sujeitos envolvidos.

O debate foi apurado como crime de tortura (lei 9.455/97) e formação de quadrilha (art. 288 do Código Penal). O acesso a tais documentos deuse por meio do Arquivo do Tribunal de Justiça do Estado de São Paulo (ATJ/SP), após este processo ter concluído suas etapas processuais e ter sido encaminhado ao arquivamento definitivo. Este caso possui uma boa quantidade de elementos probatórios em razão de ter sido apreendido em momento flagrancial (Gomes, 2017; Vargas, 2012).

Outro aspecto significativo do material decorre da narrativa da vítima que, em primeira pessoa, descreve o contexto das agressões a que foi submetida e como se desenrolou toda a ação. Há, ainda, o relato dos acusados do crime de tortura supostamente vinculados ao PCC e um caderno que continha o relato de familiares das crianças que teriam sido abusadas sexualmente pela vítima do debate, motivo pelo qual pediam 
"providências". ${ }^{3}$ As descrições de episódios de abuso sexual relatadas no caderno ajudam a compreender as categorias de justificação moral mobilizadas e que ensejaram a ação dos condutores do debate/acusados do crime de tortura. Contribuindo, inclusive, para entender como elas repercutem em relação as disputas éticas que se formulam sobre ao que competiria a justiça do crime e a justiça formal (Feltran, 2010).

A (re)construção da narrativa da vítima/acusado só foi possível em razão da especificidade de este debate ter sido interrompido pela Polícia Militar. Além de criar a possibilidade de preservar sua narrativa frente às acusações que lhe foram imputadas no âmbito do debate, permitiu aprofundar a reflexão sobre as práticas de tortura, neste caso, inscritas num contexto do funcionamento de mecanismos de controle e distribuição de punições, em que agentes privados (Jesus, 2010) se apropriaram da prerrogativa estatal de regular as relações sociais com recurso à coerção e ao uso da violência física e simbólica (Adorno; Dias, 2014).

\section{O debate: administrando a violência, fortalecendo o controle social}

Os debates constituem-se como dispositivos de arbitragem a respeito do descumprimento da ética que pauta as expectativas de comportamento e práticas do "mundo do crime" (Feltran, 2010; p. 60-63). Servem, desse modo, para regular conflitos sociais que ocorrem em relação às suas dinâmicas internas e exercer o controle social nos territórios onde a influência do PCC é mais concentrada, tal como as prisões e as "quebradas". Como mencionado, em todos os casos, ele se sustenta a partir de uma dimensão normativa assentada em moralidades amplamente difundidas e que se efetiva através da mobilização do seu poder simbólico e factual, como a ameaça ou o efetivo recurso à violência (Silvestre, 2018; Ruotti, 2016; Feltran, 2011; 2010; Hirata, 2010, Dias, 2009).

${ }^{3}$ Embora o processo não tenha tramitado com segredo de justiça, optamos por suprimir qualquer identificação do caso. 
Dias $(2009 ; 2013)$ tem ressaltado que a hegemonia do PCC não pode ser compreendida apenas pelo uso da força física. Neste aspecto, argumenta ser preciso compreender as estratégias de legitimação mobilizadas, que envolvem o desenvolvimento de narrativas político-ideológicas e morais. Assim, a exortação à necessidade de impor a "paz entre os irmãos" e o discurso de oposição ao sistema prisional colaboram significativamente para a consolidação do poder do PCC. Da mesma forma, o repúdio veemente a determinadas condutas e práticas, que, em seus estatutos, podem implicar na punição com morte, tem por base concepções éticas que sempre estiveram presentes nos procederes do crime e possui lastros em uma moralidade espraiada por amplos segmentos da população. Abusos sexuais estão dentre as práticas que contam com o mais forte repúdio e, em geral, têm como desfecho a morte dos acusados de praticá-los, ainda mais quando têm crianças como vítimas. Trata-se, justamente, da acusação que provocou o desencadeamento do debate aqui analisado.

Nessa perspectiva, o controle social exercido pelo PCC nos lugares em que se estabeleceu apresenta uma dimensão voltada à contenção de disputas e demandas dos indivíduos nos territórios, como forma de afastar e/ou reduzir a presença estatal e de impor o repertório de condutas e comportamentos que se definem como "certos" (Feltran, 2010). Isso, inclusive, porque a imposição de paz nos territórios e o afastamento das agências estatais se ancora em uma profunda desconfiança da população residente nas "quebradas" em relação às agências de repressão estatais. Em geral, a presença das agências estatais na "quebrada" se resume a atuação das polícias, comumente identificadas como expressões da opressão e injustiça perpetradas pelo Estado (Dias, 2013; 2009, Hirata, 2010; Telles; Hirata, 2010).

Através do acúmulo de pesquisas sobre a atuação do PCC, é possível elaborar e delinear alguns elementos relacionados ao procedimento do debate. Em primeiro lugar, eles não se constituem como um evento uniforme, que segue um modelo em termos de seus procedimentos. A construção do espaço do debate envolve não apenas a disponibilidade de um local adequado, mas a possibilidade de reunir as pessoas relacionadas com 
o caso que será objeto de discussão, bem como os atores que detêm a prerrogativa de adotar todos os procedimentos necessários para sua condução. Neste ponto, é importante retomar a explicação de Feltran (2010) a respeito da complexidade e gravidade do caso, especialmente se implicar a necessidade de participação de alguém que pertence às esferas mais altas da hierarquia da organização criminal, e, se esta pessoa estiver presa (como ocorre com muita frequência), será preciso, ainda, aguardar o momento mais adequado para a sua participação.

A condução do debate envolve ainda a localização do acusado/vítima, ${ }^{4}$ quando é o caso, e, muitas vezes, a sua manutenção em cárcere privado ao menos até o final da discussão e a deliberação sobre o caso, com o desfecho definido. Uma vez que o debate se assenta em um conjunto de normas de conduta que, em geral, é amplamente conhecido e reconhecido enquanto tal, o acusado/vítima pode perceber o grau do risco que está correndo quanto ao desfecho do caso, e essa percepção pode impulsionar a tentativa de fuga. Assim, a manutenção do cárcere privado durante o "desenrolar" do debate é relevante para sua consecução. Nas ocasiões em que o acusado/vítima é mantido em cárcere privado, é muito comum que, no decurso do debate, a tortura seja mobilizada para induzir a confissão, delatar outros envolvidos no problema ou como forma de punição. ${ }^{5}$ Essas ações ocorrem de forma simultânea ao próprio julgamento, antes mesmo da definição de seu desfecho.

\footnotetext{
${ }^{4}$ Nem sempre o acusado participa do debate. Isso depende de muitas variáveis, dentre elas, a gravidade do caso, de quem é o acusado e sua condição. Há situações em que a deliberação a respeito de um caso pode ser feita à revelia do acusado; isso ocorre, por exemplo, quando o acusado foge do local onde ocorreu o problema ou quando, nas prisões, ele pede transferência de pavilhão e vai para o "seguro".

${ }^{5} \mathrm{Em}$ pesquisas realizadas anteriormente no universo prisional, estes procedimentos foram largamente descritos (Dias, 2013). Segundo o Dicionário Disciplinar - documento produzido no âmbito do próprio PCC, o fato aqui poderia ser enquadrado como: "Decreto. Para confirmar um decreto a Sintonia tem que analisar com cautela, por se tratar de uma situação de vida. Tem situações que é claro o decreto, como traição, abandono, as demais situações como mão na cumbuca, caguetagem e estupros, a Sintonia analisa num contexto geral. Quando um decretado chegar em uma quebrada nossa tem que ser cobrado de bate pronto".
} 
O caso a seguir versa sobre o debate em que o acusado/vítima foi mantido em cárcere privado por supostos integrantes do PCC e submetido à prática de tortura por mais de oito horas. Para além da caracterização do debate, procuramos demonstrar como há uma configuração social e política que tem favorecido o uso de práticas de tortura por diferentes atores sociais, inclusive em contextos diversos daqueles em a tortura tem sido historicamente utilizada, qual seja, nas relações de agentes do Estado, como policiais e agentes penitenciários, em face de suspeitos e/ou pessoas sob custódia estatal (Gomes, 2017; Jesus, 2010; Lima, 1995).

\section{$* * *$}

O processo crime vai apurar a participação de nove indivíduos no debate. Os acusados se defendem ao longo do processo dos fatos que foram enquadrados como crimes de tortura (Lei. 9455/97) ${ }^{6}$ e formação de quadrilha (artigo 288 do Código Penal). ${ }^{7}$ Todos os acusados foram presos em flagrante e assim permaneceram até o desfecho final do processo, quando quatro deles foram absolvidos, enquanto os demais foram condenados apenas pelo crime de tortura e seguiram cumprindo pena privativa de liberdade.

Embora tenham sido interrogados após a apreensão em flagrante, os acusados optaram por não apresentar sua versão dos fatos na fase de inquérito policial. Neste primeiro momento, houve somente a versão da vítima e de dois policiais militares que intervieram na ação e interromperam o debate. Nesse sentido, optamos por ressaltar a seguir as narrativas que são apresentadas já na fase processual, mantendo erros de concordância e grafia, sendo que as indagações feitas pelo juiz seguem em itálico e

${ }^{6}$ Constitui crime de tortura: artigo 1o, inciso I, alínea "a": Constitui crime de tortura: I constranger alguém com emprego de violência ou grave ameaça, causando-lhe sofrimento físico ou mental, combinado com o parágrafo do 4ํㅡㄴ inciso III, § 4 을 Aumenta-se a pena de um sexto até um terço: III - se o crime é cometido mediante sequestro.

${ }^{7}$ Constitui crime de formação de quadrilha: artigo 288: Quadrilha ou bando. Associarem-se mais de três pessoas, em quadrilha ou bando, para o fim de cometer crimes: Pena - reclusão, de um a três anos. Parágrafo único - A pena aplica-se em dobro, se a quadrilha ou bando é armado. Essa redação foi alterada em 2013. 
identificamos a vítima como X. Por fim, há um esforço para apresentar estes relatos de maneira sintética, dado o espaço reduzido do texto e considerando o objetivo da discussão aqui proposta. ${ }^{8}$

\section{1 - A versão da vítima/acusado}

"Olha, você toma cuidado hoje que o pessoal do PCC está atrás de você". É assim que se inicia a descrição dos fatos por X ao juiz que apurou o caso. Ele continua: "Eu peguei e falei: Mas eu não devo nada, não tenho nada, mas eu não são, não sai, mas eu fiquei preocupado com aquilo". A vítima afirmou que desmontou a barraca em que trabalhava fazendo gravações em objetos de metal e se dirigia para sua casa, por volta das 13h, ocasião em que teria sido interceptada por um indivíduo que alegava precisar da gravação de uma pulseira para sua filha. Após conversarem sobre a execução do serviço, o indivíduo ofereceu uma carona a X, que acabou por aceitá-la por possuir problemas prévios de saúde (sofrera um AVC e possuía alguma dificuldade motora).

"Eu entrei no carro, eu vi que estava perdido, que tinha quatro pessoa dentro do carro. Eu quis sair, ele falou pra manter a calma e deixar eles me levar". A tensão inicial vai se avolumando à medida que o carro se desloca para uma outra comunidade e, nesse ínterim, ligações são feitas por outros passageiros do carro: "Consegui pegar o velho, ele tá aqui comigo, você vem?". Esses elementos sinalizam que a organização do debate já havia iniciado através da mobilização de diferentes atores e, inclusive, contava com um local para a sua execução.

Ao chegar na outra comunidade, onde o debate foi inicialmente realizado, o condutor do carro alegou: "Ô velho, aqui não tem nada de gravação, aqui é um acerto de contas, que nós temos uma acusação contra você de pedofilia, que você está abusando de criança". X reagiu dizendo ser impossível ter feito algo deste tipo, sobretudo porque sofrera um AVC. Na sequência, sofreu um espancamento inicial em que os agressores pediram ${ }^{8}$ A transcrição literal de todos os depoimentos deste caso pode ser encontrada em Gomes (2017). 
para que confessasse a prática dos atos de pedofilia. As agressões seguiram até que começou a chover, oportunidade em que, segundo ele: "me tiraram de lá [a viela] e me puseram no barraco. Estava chovendo no barraco, me amarraram, arrumaram um plástico para amarrar minha boca, canivete e alicate, falaram que iam cortar dedos meus fora (...)". Narrou ainda que ficou durante algum tempo amarrado dentro do barraco, então, por volta das onze horas da noite o debate foi interrompido por conta da chegada da polícia militar na área próximo ao local em que estavam.

Vai lá e segura eles lá, não deixa eles entrar aqui, não" ai eles foram, saíram. Para mim, eu já tinha acabado, para mim era o final, porque o policial não ia entrar lá no funcho [fundo], ele não ia entrar lá, ai eu vi que saíram uns correndo e ficou dois na porta. Quando os dois estavam ali, o policial entrou e quando ele estava entrando, os dois saíram correndo e eu sai correndo em direção do policial e o policial falou para mim: "Para, para, levanta a camisa", eu não quis nem saber o que ele estava falando, levantei a camisa, assim, e fui na direção dele. Ai eu falei para ele: "Eles estão querendo me matar", ele falou: "Calma, calma, vai lá pra a frente que tem um policial lá", que já era outro policial. Aí eu subi a viela, fui até lá e em cima e vi mais três deitados no chão e o policial do lado. Eu falei: "Eles estavam querendo me matar", "Você conhece esses três?", eu falei: "Conheço, inclusive um deles estava no comando". Aí ele [...] foi no rádio e chamou reforço, aí veio mais reforço para ajudar ele".

\section{2 - O relato dos policiais}

Os policiais foram ouvidos como testemunhas de acusação e forneceram narrativas bastante semelhantes, alegando que estavam em patrulhamento quando receberam a comunicação de que haveria um possível local de cativeiro. Dirigiram-se ao local quando "nos deparamos com quatro pessoas ao lado de um beco e em atitude suspeita, e eles esboçaram reação de fuga, momento esse que desembarcamos e detivemos os quatro, três rapazes e uma moça" (PM - 1). Na sequência, um dos policiais decidiu entrar no beco para fazer outras averiguações: 
(...) quando cheguei, mais ou menos, na metade, os indivíduos correram para o fundo da viela e depois desses indivíduos, por último apareceu a vítima pedindo socorro. Eu e a vítima subimos a viela e ele reconheceu de pronto os que a gente já havia abordado. (...) O senhor subiu com a vítima e, assim que ela viu os três no chão, já reconheceu? Como foi isso? A vítima apareceu chorando: "Eles são do PCC, estão me acusando de pedofilia e vão me matar" Eu falei: "sobe comigo". Subimos a viela e eu perguntei se os três estavam envolvidos e ela disse que sim, os três rapazes, a moça, não. Chegou a mencionar sobre os três que foram presos, esse aqui me bateu, esse aqui mandava, ou só apontou: "esses estavam"? Mencionou, só não recordo quem fez o quê (PM - 2).

\section{3 - A narrativa dos acusados/acusadores}

A versão apresentada pelos acusados pautou-se no repertório de um contexto jurídico-normativo de defesa, ou seja, todos eles apresentaram narrativas em que buscavam se desvencilhar de qualquer participação nos fatos. Diante da multiplicidade dos relatos apresentados pelos nove acusados (identificados com as iniciais de A à I), e reiterando que as indagações do juiz seguem em itálico, limitamo-nos a apresentar apenas os trechos dos depoimentos mais específicos sobre o próprio debate e/ou sessão de tortura e que mais diretamente se relaciona à discussão aqui proposta:

A - Tinha muvuca com esse negócio da vítima lá, que tinha ouvido falar? Tinha bastante gente. O que que tava rolando lá que o senhor viu? Ah, um véio que tava abusando das criança lá, entendeu, senhor? Aí eu só procurei saber, assim, aí dei uma olhadinha de relance, lá e entrei pra dentro. O senhor viu alguém agredindo a vítima? Não, no momento não, vi não, fiquei dentro de casa. Fiquei dentro de casa memo, só saí quando aconteceu, a polícia bateu na minha porta e me tirou de dentro de casa, entendeu senhor?

B - O senhor encontrou com ele e falou exatamente o que pro senhor? Falou, né, que tinha ficado sabendo de um suposto pedófilo. Ai não, mano, tem um pedófilo aí... Tá ali embaixo ali, aí falei pra ele, vamo encostar lá, né? Curiosidade. Também sou pai de família, também, desci lá. O pedófilo tá lá embaixo, o que que tá acontecendo com ele, ele falou? Aí num sei, eu desci 
pra saber o que tava acontecendo. Falou que tinha um pedófilo lá, entendeu? Aí nós descemos pra ver o que que era. Ele num falou? Tava lá, tava lá né? Com a mãe das criança, com um pessoal lá, nós descemos. Aí o senhor foi lá por quê? E foi até lá por quê? Por curiosidade. Por curiosidade, do quê? De saber quem era, se era algum conhecido. Se conhecíamos, se era de lá mesmo. Que o senhor fez? Entrou no barraco? Desci lá, na hora que eu fui lá ele não tava no barraco, senhor. Ele não tava no barraco? Tava na viela, tava na viela, tipo sentado, assim, nos blocos. O que que o senhor fez? O senhor conversou com ele? Conversei com ele né, pra ver o que que aconteceu, no momento que eu estava lá, já tinha umas pessoas lá que já tava mais exaltada, uma tava controlando, já querendo bater, né? Né, hum, inclusive teve até um momento que eu intercedi lá pro pessoal que queria bater nele. Eu falei, "Não, não, vamo procurar saber se é isso mesmo, né?". Pra num fazer uma injustiça. Aí, foi na hora que eu fiquei lá uns 15/20 minutos e subi de volta nessa viela, fiquemos lá em cima. E nesses 15/20 minutos a vítima foi agredida? Não senhor, pessoal que tava lá, tinha uns que eu conhecia, uns que eu não conhecia. No momento ninguém deixou encostar a mão nele não. Pelo que eu vi até antes não tinha encostado também, porque ele não tinha nenhuma inchação, não tinha nada, entendeu? E quem tava mantendo a vítima presa, ali? Não, não tinha ninguém mantendo. Ela tava sentada. (...) Tava mantendo a vítima ali? Eu tô acusando um velho de pedofilia ele vai ficar esperando? Não, mas que conta também, num tinha resistência.

C - O senhor quer declarar alguma coisa? Igual, no caso, o ocorrido, foi que tava tendo um comentário dum pedófilo na comunidade. Onde que eu, com curiosidade, (...) quando o B veio na moto dele, aí ó, tá tendo o comentário dum pedófilo, vamo lá dá uma aperriada, né rapaz? Vai que reconhece, aí né, uma questão de um ou dois minuto. Aí nós, né, fomo, vimo aí ele e ele viu nós, aí saiu fora, mais dez minuto chegou três viaturas. Passou por nós, voltou, aí quando voltou, aí passou correndo, como nós num devia, fiquemo lá. Já chegou dando uma pá de tiro lá, aí foi procurar, nós fiquemos na mão de um dos soldados o outro desceu a viela, aí que saiu um velho de lá falando que ia morrer, pelo amor de deus. Aí esse era o pedófilo que o senhor viu? É o pedófilo.

Os demais acusados (D, E, F, G, H, I) deram relatos que não mencionavam o local, tampouco algum elemento sobre as práticas de tortura. Como resposta à pergunta feita pelo juiz a respeito da existência de um pedófilo 
na comunidade, o acusado D afirmou desconhecer tal assunto: "Não, até o momento, assim, não. Tinha um monte de gente na favelinha onde eu moro, mas num tinha nenhum comentário". Outros acusados argumentaram que sequer estiveram próximos ao local dos fatos porque estariam em outros lugares, ou ainda, no cumprimento da jornada de trabalho, como foi o caso de E, F e G:

E - A polícia civil ou militar que prendeu o senhor? Militar. O senhor ficou sabendo que já tinham pego lá um tal dum pedófilo? Que tava lá um velho, no fundo? Não sabia. O senhor não passou? Não viu nada lá? Não, porque eu trabalhei o dia todo, num saí de lá da casa do meu vizinho.

F - O senhor ouviu algum comentário, alguma história, de que iam pegar um pedófilo que tava abusando das crianças do bairro? Não, não ouvi nenhum comentário, não. Não ouviu nada sobre isso? Não, porque eu passo a tarde todinha trabalhando. Já foi preso ou processado alguma vez? Não, nunca fui preso.

G - E o senhor não percebeu que tava acontecendo alguma coisa lá no barraco? Não? No barraco embaixo, lá do fundo? Não, porque eu cheguei à noite da casa da minha irmã, tava... Eu fui direto dormir, aí quando eu acordei, a polícia já tava. Tava dois policiais com as armas apontadas pra mim, pedindo pra eu acompanhar eles até a viatura, aí, na rua.

Por fim, os relatos de $\mathrm{H}$ e I acentuaram como a abordagem policial teria sido o motivo que determinou a acusação feita sobre eles. Além disso, ressaltaram como o fato de serem egressos do sistema prisional teria sido também um fator que contribuiu para suas detenções.

$\mathbf{H}$ - (...) foi no meio do caminho, me pegaram e me levaram pra delegacia. Chegando na delegacia, eles tavam alegando que eu tava fazendo parte de um negócio do tribunal do crime, foi onde ele começou a fazer várias perguntas pra ver se eu tava envolvido. Aí respondi tudo certinho, num tenho necessidade, ele "não, cê mora lá". Tô tentando me regenerar, voltar pra dentro da sociedade, cê tá fazendo isso comigo? 
I - O senhor sabe do que está sendo acusado, num sabe? O senhor quer declarar alguma coisa? É, em questão do dia (-) eu tava vindo da casa da minha mãe né, indo sentido para minha casa (...) eu fui abordado pela viatura da tático. Onde os policiais perguntou se eu tinha passagem, eu falei que tinha sim uma passagem, de 2001, no qual eu não devia mais, da qual eu tinha cumprido tudo, só que eu estava sem a minha documentação, que eu tinha deixado na casa da minha mãe. (...) [O policial] me entregou um papel com um monte de coisa escrito [...] supostamente que eu tinha sequestrado o senhor, um rapaz lá, que eu tinha torturado lá o rapaz, que eu tinha participação com o crime organizado, enfim, assinou o papel lá e me botou pra trás a noite inteira desse jeito. Me tiraram da (-) e me levaram pro CDP.

\section{4 - O relatório do crime: regulação social e os valores morais comunitários}

Um caderno foi encontrado no local do debate e apresentado como prova da acusação. Nele, havia o registro detalhado da acusação de pedofilia, elaborado na forma de um relatório, descrevendo as demandas que diversas pessoas da comunidade haviam levado ao conhecimento de indivíduos supostamente vinculados ao PCC. Neste relatório, há uma descrição detalhada das práticas libidinosas que teriam sido praticadas por $\mathrm{X}$ e, ainda, um registro dos pedidos por providências ("cobranças") realizados por familiares das crianças supostamente abusadas. Segue um trecho:

Obs: o velho confirmou para nós que abuzou (sic) somente do (-) e falou que fez com o mesmo (-). Mas antes disso confirmou para nosso irmão (-) que tinha feito (-). Mãe: (-) mesma é mãe de um e tia dos outros 3 aonde não estar de acordo com essa situação e também é entendida da disciplina do crime e em cima disso quer uma cobrança. Mãe (-) a mesma é mãe do (-) e não está de acordo com essa situação e quer uma cobrança. Cunhado (-) o mesmo é cunhado dos meninos e é entendido do crime e quer cobrança. Obs: Assim a dona (-) chegou no (-) passando o que estava acontecendo aonde teve um dia que ela encontrou um dos seus filhos no colo do velho e o velho brincou com ela dizendo que queria o menino para ele (...) depois disso ele pediu $\mathrm{p} /$ ela levar os meninos num passeio. 
Embora a descrição contida no caderno tenha sido reduzida para não identificar nenhuma informação específica quanto às práticas libidinosas/ sexuais e quanto aos envolvidos no caso, pode-se extrair que as mães foram as principais demandantes de providências aos indivíduos que, na comunidade, eram identificados como detentores da prerrogativa de efetuar a "cobrança" ao acusado de pedofilia, nos termos do procedimento de regulação social posto em prática através do mecanismo de debate. Um outro aspecto importante é a menção ao fato de que alguns dos demandantes da "cobrança" eram "entendidos do crime", ou seja, o PCC é procurado com a expectativa de que resolva o caso, atuando de acordo com repertório de ação e valores que pautam as regras do mundo do crime (Ruotti, 2016; Dias, 2009).

Há, portanto, uma compreensão de que o PCC possuiria legitimidade de incidir em relação aos fatos considerados como graves e sensíveis para a comunidade. Neste caso, o recurso da violência física figura aqui como um aspecto relevante não apenas para aqueles que estão inseridos no "mundo do crime", mas igualmente para quem detém algum conhecimento quanto aos valores e códigos vigentes neste universo moral, como foi o caso das mães que ativamente procuraram os supostos membros da organização ou, ainda, daqueles que eventualmente presenciaram o espancamento de $X$ na viela (Ruotti, 2016).

Nota-se, portanto, que o debate também possibilita que o próprio PCC busque consolidar a narrativa factual de que é capaz de dar conta das demandas de regulação social que recebe da comunidade e tratálas através de um mecanismo que opera a partir de uma concepção de justiça, utilizando como paradigmas valores que fazem parte do proceder do crime, expressos, inclusive, no estatuto e outros documentos do PCC (Ruotti, 2016; Dias, 2009). Tais valores estão socialmente disseminados e fortemente ancorados culturalmente, mobilizando moralidades e fortes sentimentos de repulsa, como ocorre no caso analisado aqui, em que os supostos abusos sexuais de $\mathrm{X}$ contra as crianças justificariam o uso da violência física e psicológica contra o acusado/vítima. 


\section{O duplo no espelho}

Um elemento peculiar que emerge da análise dos documentos aqui descritos é o papel duplamente invertido que os atores envolvidos no evento desempenham (Goffman, 2014), considerando-se o fenômeno social do debate e a apuração do fato pelo sistema de justiça criminal, registrado no processo judicial. O contexto social, político e institucional é um fator fundamental para distinguir e situar a posição dos atores e o desempenho de seus papeis.

Desta forma, no âmbito do processo judicial, $\mathrm{X}$ aparece na posição de vítima, sobressaindo em suas narrativas sua submissão frente aos agressores, o abuso psicológico, o controle físico e os diferentes tipos de agressão que Ihe foram dirigidas e que ressaltam a sua vulnerabilidade, o que, inclusive, constituiu parte de como o debate em si foi operacionalizado. Além disso, por ser tratado como vítima pelo sistema de justiça criminal, é perceptível como sua narrativa visa estabelecer uma oposição frente às narrativas apresentadas pelos acusados, especialmente porque a produção da verdade sobre os "fatos" no sistema de justiça perpassa a eleição de qual versão, seja a da vítima, a do acusado ou das testemunhas, é aquela mais crível para seus agentes e definirá o desfecho do caso (Gomes, 2017; Lima, 1989).

Por sua vez, no julgamento informal posto em prática através do debate, X está caracterizado pelo papel de agressor sexual de crianças, conforme as narrativas descritas no caderno e o depoimento dos envolvidos no debate revelam. Neste caso, ocorre um deslizamento para a posição de agressor, e a imagem dele é construída a partir de atos que envolvem o constrangimento de suas vítimas, as quais teriam sido submetidas a diferentes tipos de abusos e de violências. Dessa forma, coloca-se em evidência a sua capacidade de agredir e violar crianças vulneráveis e não as suas limitações físicas e psicológicas.

Enquanto isso, em relação aos supostos membros do PCC, o papel por eles desempenhado está intimamente vinculado à percepção de legitimidade de que usufruem. Nesse sentido, as variações quanto à legitimidade desses 
agentes se associa ao contexto em que elas operam. Assim, quando são procurados pelas mães das crianças para que julguem e punam $X$, sua legitimidade se percebe pela compreensão daquelas mulheres de que estes agentes seriam capazes de atender essa reinvindicação de acordo com as regras e valores vigentes no mundo do crime (Ruotti, 2016).

Todavia, quando estão submetidos ao processamento legal, passam a ser caracterizados como agentes ilegítimos para efetuar qualquer tipo de punição e, sendo assim, as iniciativas para resolver o problema que lhes foram demandadas são reinterpretadas à luz do código penal e, dessa forma, criminalizadas (Misse, 2008). Nesse sentido, o enquadramento do debate enquanto um crime (tortura/quadrilha) destaca como certos eventos, quando submetidos à análise do sistema de justiça criminal, são delineados a partir dos repertórios de definições jurídico-normativas e valores vigentes nessas instituições (Misse, 2008), especialmente porque a aplicação de punições juridicamente legais é aquela definida por um juiz de direito. Por consequência, as ações e os executores (do debate) são inevitavelmente considerados como agentes ilegais. O sistema de justiça retoma para si a prerrogativa de produzir o julgamento das condutas dos indivíduos e, eventualmente, punir de acordo com a lei, reivindicando o princípio do monopólio do uso da violência legítima pelo Estado (Adorno; Dias, 2014).

\section{A prática da tortura no "debate" - convergências possíveis}

No debate de "vida e morte" (Feltran, 2010) aqui relatado, o uso da violência física e psicológica foi mobilizado durante toda a sua execução. Além disso, pode-se perceber como, desde o início, sobressaiu-se o interesse de que a vítima confessasse os abusos que teria praticado contra as crianças da comunidade. Nesse aspecto, observa-se como a prática da tortura desponta tanto através dos meios utilizados (agressões e ameaças), com o objetivo de extrair a confissão de $X$, como também como um fim em si mesmo, como forma de impor a punição ao acusado de praticar um 
ato que contraria frontalmente os dispositivos normativos e os valores da comunidade e do mundo do crime.

Ademais, o relatório elaborado pelos acusados de realizar o debate atesta que: "Obs: o velho confirmou para nós que abuzou (sic) somente do (-) e falou que fez com o mesmo (-). Mas antes disso confirmou para nosso irmão (-) que tinha feito" (grifo nosso). A suposta confirmação dos abusos ocorreu no âmbito do debate, isto é, num contexto em que a vítima já estaria subjugada. Portanto, as torturas infligidas a ela pretendiam obter a confirmação das imputações que Ihe foram atribuídas a fim de que a punição imposta estivesse respaldada pelas diretrizes que sustentam a atuação do PCC, as quais se legitimam a partir de concepções de justiça que fundamentam essa atuação e que supõem a comprovação dos atos que desencadearam o mecanismo punitivo. Assim, tanto mais importante é a confissão como prova das acusações que o levaram ao debate, em razão de que o desfecho provável de casos de abuso sexual de crianças é a punição com a morte, o que demanda a certeza da culpa para que a punição não seja interpretada com injusta.

Contudo, considerando-se a própria configuração do debate, nos termos antes descritos, seria possível cogitar que a narrativa de $\mathrm{X}$ poderia ser acolhida de outra forma, senão como a confirmação de sua culpa? Independentemente desta confirmação, as práticas de tortura mobilizadas por meio do debate e a conformação mesma do contexto do julgamento em detrimento da vontade da vítima correspondem ao poder que o PCC reivindica dispor sobre a vida e a morte dos segmentos da população que vivem nos territórios sob seu controle (Dias, 2009).

Neste sentido, quando pessoas da comunidade, não necessariamente com vínculos com o crime, procuraram o PCC, podemos perceber que há uma expectativa de que esses agentes seriam capazes de responder às suas reinvindicações, inclusive com uma sanção mais efetiva diante de atos tão graves. Importante considerar aqui que "as injustiças cometidas contra as crianças constituem um território moral politicamente muito lucrativo para aqueles que conseguem se legitimar como representantes da luta contra 
essas injustiças" (Lowenkron, 2013, p. 311). Ademais, as moralidades em torno do abuso sexual em face de crianças e adolescentes fundamentamse em uma percepção que transcende a visão do crime, encontrando eco em uma reprovação mais difusa na sociedade brasileira, ${ }^{9}$ ainda que essa condenação ocorra mais no plano discursivo do que na realidade concreta - haja vista os números sobre violência sexual no país. Dessa forma, se o desfecho do debate fosse o homicídio do acusado de pedofilia, essa morte não ensejaria necessariamente um desconforto social ou uma reprovação moral, mas, ao contrário, poderia ser percebida como justa e adequada à gravidade do ato cometido.

A partir de pesquisa desenvolvida em dois bairros periféricos na cidade de São Paulo, Ruotti (2016) destaca como a percepção da população local em relação ao PCC conta com uma série de duplicidades quanto aos elementos "segurança" e "proteção" que o grupo criminal confere à localidade. Assim, quando se aciona o PCC como instância capaz de resolver conflitos de diferentes tipos, presume-se que a organização terá condições de dar uma resposta adequada, sabendo-se que, possivelmente, isso implicará a utilização de expedientes violentos, ou ainda a violência letal. No caso em análise, tratando-se de um tipo de imputação bastante grave no repertório moral presente em diversos segmentos sociais, o uso da violência não parece ter sido um óbice ou ter provocado constrangimento. No relato da vítima, inclusive, percebe-se que várias pessoas presenciaram e/ou participaram da agressão sem interceder por ela.

Porém, apesar de compreender que há uma convergência moral que envolve toda a comunidade - os integrantes do mundo do crime e demais moradores -, não é possível atribuir apenas a essa confluência a ausência de pessoas que tenham tentado interceder ou evitar as agressões, como se extrai, por exemplo, do fato de os policiais terem chegado ao lugar após

${ }^{9}$ O Estudo do Instituto de Pesquisa Econômica Aplicada (IPEA) (2017) destaca como o estupro de vulnerável (em crianças e adolescentes com menos de 13 anos) constitui quase $70 \%$ das ocorrências de violência sexual no país, ressaltando-se que esse tipo de violência costuma ter como agressores indivíduos que conhecem a vítima, com destaque para aqueles que compõem o círculo intrafamiliar (pais, padrastos, avôs). 
terem sido informados pela comunicação interna da PM de que haveria uma pessoa mantida em cativeiro. O medo imposto pelos atores do crime sobre as pessoas que vivem nas localidades onde eles detêm a prerrogativa de efetivar essa gestão da violência deve também ser considerado como um fator relevante para compreender a complexidade dessas relações.

Em um dos casos discutidos em Ruotti (2016), membros do PCC que realizavam a decisão de um debate de execução do acusado disseram aos vizinhos do local onde os fatos ocorreram que se "abrissem o bico" o mesmo aconteceria com eles. Porém, alguns desses vizinhos, sensibilizados pelo esforço da família de uma das vítimas do debate, acabaram colaborando com informações quando o caso foi apurado pela justiça formal (Ruotti, 2016).

Além disso, é possível destacar como a extração da confissão por meio da tortura não é um fato desconhecido da realidade social brasileira. A atividade policial tem recorrido historicamente à tortura e, consequentemente, às confissões obtidas a partir dela, inclusive incorporando-a como modus operandi de muitas investigações criminais no país. Por conseguinte, pode-se dizer que se trata de prática incorporada na atuação do próprio sistema de justiça criminal (Barros, 2015; Vargas, 2012; Lima, 1995; Mingardi, 1991).

Ao submeter um suspeito à tortura (em diferentes graus e modalidades), um agente policial visa, via de regra, obter uma confissão ou punir o indivíduo, sujeitando-o à sua vontade. Esse domínio que o agente policial exerce sobre o sujeito sob sua custódia encontraria respaldo em justificativas que supostamente legitimariam essa prática. Dessa forma, valores corporativistas quanto ao emprego da violência, a percepção calcada em julgamentos morais e valores amplamente aceitos na sociedade de que os suspeitos são "vagabundos" e, ainda, a "inevitabilidade" da tortura para alcançar um determinado propósito seriam elementos centrais nesse tipo de ocorrência (Barros, 2015). Portanto, pode-se considerar que a mobilização da tortura se baseia também nos valores sociais que circulam mais amplamente na sociedade, independentemente do contexto em que essa prática é acionada. Além disso, os agentes que dela se utilizam, procuram reforçar 
internamente, frente ao grupo ao qual pertencem, a justificativa para o seu uso. Paradoxalmente, isso pode ser observado tanto no debate executado pelo PCC quanto em relação à tortura empreendida por agentes policiais.

Outro fator decorrente da conformação do contexto propício às práticas de tortura é a restrição da liberdade de locomoção da vítima, ainda que de forma situacional, dentro do quadro temporal necessário para a imposição da violência. O impedimento da locomoção garante que a prática violenta se estenda no tempo e alcance seu objetivo, seja a obtenção da confissão ou a punição. O domínio de um indivíduo pelo outro é o elemento central no âmbito da tortura, que permite a subjugação e, desta forma, a intervenção violenta sobre o corpo do sujeito, muitas vezes, posicionado nesta relação como "objeto" (Gomes, 2017).

No debate aqui analisado, nota-se que a submissão da vítima em face dos supostos membros do PCC é o primeiro elemento que aparece no seu relato, quando entra no carro e é deslocada para outra comunidade e colocada numa situação em que se torna incapaz de reagir. Além disso, as torturas a que foi submetida desde o início do debate ressaltam sua impossibilidade de se desvencilhar do controle a que está sujeitada, e essa configuração de restrição física se altera somente quando a polícia interrompe o debate e a vítima consegue fugir do domínio dos agressores. O caso aqui analisado nos permite identificar uma miríade de elementos que são mobilizados - restrição física da vítima, imposição de diferentes tipos de agressões, extração de uma confissão - que correspondem a fatores presentes nas práticas de tortura amplamente disseminadas no país (Gomes, 2017).

\section{Considerações finais}

Os debates tornaram-se um dispositivo relevante na atuação do PCC, caracterizando-se como sendo capazes de regular conflitos sociais e gerir o emprego da violência nos lugares em que o grupo alcançou hegemonia, 
como nas prisões paulistas e nas periferias (Feltran, 2010; Dias, 2013). O apoio às suas ações não decorre apenas do emprego efetivo da violência, mas também se fundamenta na conformidade aos valores que são socialmente disseminados. Desse modo, esses repertórios têm contribuído para reforçar a relevância do PCC na gestão dos conflitos sociais, bem como ajudam a legitimar suas ações, ainda que violentas, para aqueles que enxergam no grupo a capacidade de prover "justiça".

O caso aqui analisado permitiu observar como práticas de tortura foram mobilizadas durante a execução desse debate do tipo "vida e morte". Dessa forma, a restrição física imposta à vítima, a necessidade da obtenção de uma confissão, bem como a variedade de agressões contra ela dirigidas constituíram-se como elementos presentes durante a ocorrência do debate. Por outro lado, externalizam como tais características estão igualmente presentes em outros contextos em que práticas de tortura têm sido historicamente utilizadas, como é o caso daquelas que ocorrem em delegacias de polícia e nas prisões.

Além disso, foi possível compreender como a disposição individual de membros do PCC quanto ao uso da violência também decorre dos repertórios morais amplamente difundidos entre a população, como é o caso do abuso de crianças, e que estes são muito mais amplos do que as regras vigentes no mundo do crime. Dessa forma, outras referências quanto à moralidade sexual, de gênero e de classe são também relevantes para que estes mesmos agentes possam balizar suas decisões subjetivamente e quanto às interpelações que são provocadas por agentes externos. Finalmente, um contexto político e social de completa falta de confiança nas instituições estatais formais para resolver o problema dos segmentos mais vulneráveis da população está no cerne do fenômeno aqui analisado (Adorno; Dias, 2014).

Esse fator ajuda, inclusive, a compreender como, em alguns casos, princípios morais e interesses sociais socialmente difundidos dão sustentação à ação do PCC, elegendo-o como instância produtora de justiça, inclusive pela possibilidade de uso da violência fatal, sem que isso seja de todo modo desencorajado - e que teria sido possivelmente o desfecho desse 
caso, se o debate não tivesse sido interrompido. Ao mesmo tempo, o fato de uma denúncia ter provocado a ida da polícia ao local dos fatos sugere que a legitimidade do PCC para impor punição e fazer justiça não é estável, homogênea ou consensual e está sujeita a atualizações permanentes.

Desse modo, pode-se indicar que o debate em si possui uma interpretação polissêmica e que os membros do PCC são identificados a partir de signos e representações ambivalentes. De um lado, segmentos da população depositam a confiança neles como agentes capazes de aplicar a justiça de uma forma mais adequada que o Estado; por outro, essa mesma prerrogativa que lhes é atribuída advém, em parte, de se tratar de um grupo criminal armado, de reconhecido poder coercitivo, o que, obviamente, provoca o sentimento de medo nesta mesma população (Ruotti, 2016). Finalmente, pode-se observar, ainda, que práticas de tortura se têm adaptado a diferentes contextos na realidade brasileira. Isso sugere que novas formas de as interpretar precisam estar conectadas às mudanças sociais pelas quais a sociedade passou ao longo das últimas décadas, sobretudo, em relação às reconfigurações produzidas pela emergência de novos atores sociais criminais que assumem papeis ambivalentes e acabam por atualizar o sentido de práticas autoritárias e arbitrárias historicamente associadas às agências estatais nos mecanismos que acionam para reprimir o crime.

Camila Nunes Dias é Doutora em Sociologia, Professora da Universidade Federal do ABC, Pesquisadora do CNPq, Coordenadora do Grupo de Pesquisa em Segurança, Violência e Justiça - SEVIJU e pesquisadora colaboradora do Núcleo de Estudos da Violência (NEVUSP). $\bowtie$ camila.dias00@gmail.com

Mayara de Souza Gomes é doutoranda em Ciências Humanas e Sociais pela Universidade Federal do ABC, Mestra pelo mesmo programa (2017) e membro do grupo de pesquisa em Segurança, Violência e Justiça - SEVIJU da UFABC. $₫$ mayara.dsgomes@gmail.com 


\section{Referências}

1. ADORNO, Sérgio; SALLA, Fernando. Criminalidade organizada nas prisões e os ataques do PCC. Estudos Avançados, v. 61, n. 21, p. 7-29, 2007. https://doi. org/10.1590/S0103-40142007000300002

2. ADORNO, Sérgio; DIAS, Camila C. N. Monopólio estatal da violência. In: LIMA, Renato S. de; RATTON, José L.; AZEVEDO, Rodrigo G. de (orgs.). Crime, polícia e justiça no Brasil. 1. ed. São Paulo: Contexto, 2014. p. 187-197. (v. 1).

3. BARROS, Marcelo. Polícia e tortura no Brasil: Conhecendo a caixa das maçãs podres. 1. ed. Curitiba: Appris, 2015.

4. BIONDI, Karina. Etnografia no movimento: Território, hierarquia e lei no PCC. Tese (Doutorado em Antropologia Social) - Universidade Federal de São Carlos, São Carlos, 2014.

5. BIONDI, Karina. Junto e misturado: Imanência e transcendência no PCC. Dissertação (Mestrado em Antropologia Social) - Universidade Federal de São Carlos, São Carlos, 2009.

6. CALDEIRA, Teresa P. do R. Cidade de Muros: Crime, segregação e cidadania em São Paulo. São Paulo: Editora 34; Edusp, 2000.

7. CALDERONI, Vivian; JESUS, Maria Gorete M. (coord.). Julgando a tortura: Análise de jurisprudência nos tribunais de justiça do Brasil (2005-2010). São Paulo: ACAT-Brasil/Conectas/NEV-USP/IBCCRIM/Pastoral Carcerária, 2015.

8. CERQUEIRA, Daniel; COELHO, Danilo. S. C; FERREIRA, Helder. Estupro no Brasil: Vítimas, autores, fatores situacionais e evolução das notificações no sistema de saúde entre 2011 e 2014. Brasília: Instituto de Pesquisa de Econômica Aplicada, 2017.

9. DIAS, Camila C. N. PCC: Hegemonia nas prisões e monopólio da violência. 1. ed. São Paulo: Saraiva, 2013. 455 p. (v. 1).

10. DIAS, Camila C. N. Estado e PCC tecendo as tramas do poder arbitrário nas prisões. Tempo Social, v. 23, n. 2, p. 213-233, 2011.

11. DIAS, Camila C. N. A disciplina do PCC: a importância do (auto) controle na sociabilidade prisional. Revista Brasileira de Ciências Criminais, v. 18, p. 393-414, 2010.

12. DIAS, Camila C. N. Ocupando as brechas do direito formal: O PCC como instância alternativa de resolução de conflitos. Dilemas: Revista de Estudos de Conflito e Controle Social, v. 2, n. 4, p. 83-105, 2009.

13. DIAS, Camila N.; SALLA, Fernando. Violência e negociação na construção da ordem nas prisões: a experiência paulista. Sociedade e Estado, v. 34, p. 539-564, 2019. 
14. FELTRAN, Gabriel S. Manter a ordem nas periferias de São Paulo: Coexistência de dispositivos normativos na "era PCC". In: AZAIS, Cristhian; KESSLER, Gabriel; TELLES, Vera S. (orgs.). Ilegalismos, cidade e política. 1. ed. Belo Horizonte: Fino Traço, 2012. p. 100-125.

15. FELTRAN, Gabriel S. Fronteiras de tensão: Política e violência nas periferias de São Paulo. 1. ed. São Paulo: Editora Unesp/CEM, 2011.

16. FELTRAN, Gabriel. S. Crime e castigo na cidade: Os repertórios da justiça e a questão do homicídio nas periferias de São Paulo. Caderno CRH, v. 23, n. 58, p. 59-73, jan./abr. 2010. https://doi.org/10.1590/S0103-49792010000100005

17. GINZBURG, Carlo. Mitos, emblemas, sinais: Morfologia e história. São Paulo: Companhia das Letras, 1989.

18. GODÓI, Rafael. Fluxos em cadeia: A prisão em São Paulo na virada dos tempos. 1. ed. Boitempo, 2015.

19. GOFFMAN, Erving. A representação do eu na vida cotidiana. 20. ed. Rio de Janeiro: Editora Vozes, 2014.

20. GOMES, Mayara de S. Isso é tortura? Disputas, consensos e narrativas na construção social do crime de tortura na cidade de São Paulo. 2017. Dissertação (Mestrado em Ciências Humanas e Sociais) - Universidade Federal do ABC, São Bernardo do Campo, 2017.

21. HIRATA, Daniel V. Sobreviver na adversidade: entre o mercado e a vida. 2010. Tese (Doutorado em Sociologia) - Faculdade de Filosofia, Letras e Ciências Humanas da Universidade de São Paulo, São Paulo, 2010.

22. JESUS, Maria Gorete M. O crime de tortura - uma análise dos processos criminais na cidade de São Paulo. São Paulo: IBCCRIM, 2010.

23. JOZINO, Josmar. Cobras e lagartos: A verdadeira história do PCC. 2. ed. São Paulo: Via Leitura, 2017.

24. LIMA, Roberto K. A polícia da cidade do Rio de Janeiro: Seus dilemas e paradoxos. 2. ed. Tradução de Otto Miller. Rio de Janeiro: Forense, 1995.

25. LIMA, Roberto K. Cultura Jurídica e práticas policiais: A tradição inquisitorial. Revista Brasileira de Ciências Sociais, v. 4, n. 10, p. 65-84, 1989.

26. LOWENKRON, Laura. O monstro contemporâneo: notas sobre a construção da pedofilia como "causa política" e "caso de polícia". Cadernos PAGU, n. 41, p. 303-337, jul./dez., 2013.

27. MACHADO, Marta R. A.; MACHADO, Maíra R.; MATSUDA, Fernanda. E; FERREIRA, Luísa M. A; FERREIRA, Carolina C. Massacre do Carandiru + 23. In: MACHADO, Maíra R.; MACHADO, Marta R. A. (coord.). Carandiru não é coisa 
do passado: um balanço sobre os processos, as instituições e as narrativas 23 anos após o massacre. São Paulo: FGV Direito, 2015.

28. MANSO, Bruno P.; DIAS, Camila. N. PCC, sistema prisional e gestão do novo mundo do crime no Brasil. Revista Brasileira de Segurança Pública, v. 11, n. 2, p. 10-29, 2017.

29. MARQUES, Adalton. Crime, proceder, convívio-seguro. Um experimento antropológico a partir de relações entre ladrões. Dissertação (Mestrado em Antropologia Social) - Faculdade de Filosofia, Letras e Ciências Humanas, Universidade de São Paulo, São Paulo, 2009.

30. MISSE, Michel. Sobre a construção social do crime no Brasil. Esboços de uma interpretação. In MISSE, Michel (organizador). Acusados e Acusadores. Rio de Janeiro: Revan, 2008, pp. 13-32

31. MINGARDI, Guaracy. Tiras, gansos e trutas - cotidiano e reforma na polícia civil. São Paulo: Scritta Editorial. 1991

32. OLIVEIRA, Fabiana L. de; SILVA, Virgínia F. Processos judiciais como fonte de dados: Poder e interpretação. Sociologias, v. 7, n. 13, p. 244-259, jan./jun. 2005.

33. RAMALHO, José R. O mundo do crime: A ordem pelo avesso. 3. ed. São Paulo: IBCCRIM, 2002.

34. RUOTTI, Caren. Pretensão de legitimidade do PCC: justificação e reconhecimento de suas práticas na periferia de São Paulo. Tese (Doutorado em Sociologia) - Faculdade de Filosofia e Ciências Humanas, Universidade de São Paulo, São Paulo, 2016.

35. SILVESTRE, Giane. Controle do Crime e seus operadores: política e segurança pública em São Paulo. 1. ed. São Paulo: Annablume, 2018.

36. SHIMIZU, Bruno. Solidariedade e gregarismo nas facções criminosas. 1. ed. São Paulo: IBCCRIM, 2011.

37. TEIXEIRA, Alessandra. Prisões da exceção: Política penal e penitenciária no Brasil contemporâneo. 1.ed. São Paulo: Juruá Editora, 2009.

38. TELLES, Vera S.; HIRATA, Daniel V. Ilegalismos e jogos de poder em São Paulo. Tempo Social: Revista de Sociologia da USP, v. 22, n. 2, p. 39-59, 2010.

39. VARGAS, Joana D. Em busca da "verdade real": tortura e confissão no Brasil ontem e hoje. Sociologia \& Antropologia, v. 2-3, 2012, p. 237-265.

Recebido em: 9 jul. 2020. Aceito em: 15 fev. 2021. 
